\title{
The Use of IIEF-5 for Reporting Erectile Dysfunction Following Nerve-Sparing Radical Retropubic Prostatectomy
}

\author{
Maarten Albersen, Steven Joniau* and Hendrik Van Poppel
}

Department of Urology, University Hospitals Leuven, Leuven Belgium

\begin{abstract}
Introduction: Increased detection of organ-confined prostate cancer has led to an increased demand for nervesparing surgery. Most studies of erectile dysfunction (ED) following nerve-sparing radical prostatectomy (RRP) use single-item assessment, and potency rates differ widely among various groups. We aimed to investigate the use of the IIEF-5, a validated questionnaire, for reporting ED following RRP.

Aims: To study the use of the IIEF-5 questionnaire in the evaluation of post-RRP ED, and to find possible variations in ED reporting when comparing IIEF-5 to single-item assessment.

Methods: At a minimum of 18 months post-surgery, patients completed a questionnaire on erectile function that included both single-item assessment and the IIEF-5. The study included sexually active patients who reported no pre-operative ED and who did not receive adjuvant or salvage therapy.

Main Outcome Measures: For the single-item assessment, potency was defined as "the ability to achieve erections firm enough for intercourse". For the IIEF-5 questionnaire, potency was defined as a score $\geq 22$ (out of 25) points.

Results: Ninety-one patients were included in the study. The procedures consisted of bilateral nerve-sparing (55\%) or unilateral or partial bilateral nerve-sparing surgery $(45 \%)$. We found a striking difference in potency rates when using either IIEF-5 score or single-item assessment for reporting of potency after RRP. The results when using the IIEF-5 questionnaire indicated that $25.5 \%$ of all patients were potent. In contrast, single-item assessment indicated a potency rate of $53.8 \%$.

Conclusions: Using the IIEF-5 questionnaire to evaluate ED following RRP results in a remarkably lower percentage of men being classified as having no ED. This might be the main reason IIEF-5 is not frequently used in the reporting of ED following radical prostatectomy. Literature search reveals that the IIEF-5 questionnaire is expected to have a higher level of validity, accuracy, and reliability, and may be more stable than single-item assessment. We think that the use of IIEF-5 in the reporting of ED following RRP enhances comparison of different series and of different treatment modalities. However, a prospective comparison between IIEF-5 and single-item assessment is needed to confirm this finding.
\end{abstract}

\section{INTRODUCTION}

Prostate cancer is a medical problem affecting many men. An estimated 301.500 new cases are diagnosed each year in the European Union, where prostate cancer constitutes about $24 \%$ of all male cancers [1]. At present, radical retropubic prostatectomy (RRP) is the treatment of choice in young men with clinically localized prostate cancer [1]. Increased screening using prostate-specific antigen has resulted in the detection of mostly clinically localized prostate cancer at earlier stages and in younger men; therefore, patients undergoing radical prostatectomy generally have good baseline erectile function and high expectations concerning the preservation of erectile function following the procedure. Since Walsh et al. published their insights into the etiology and prevention of impotence following RRP in 1982, their nervesparing technique has been widely employed to improve postoperative erectile function. The anatomical techniques used in RRP results in decreased blood loss and thus better visualization and safer dissection of the neurovascular bundles $[2,3]$. Many studies on erectile dysfunction (ED) following nerve-sparing RRP have been published, revealing widely disparate potency rates (30-86\%) among various groups in different studies [4-11]. This variation in potency

*Address correspondence to this author at the Department of Urology, University Hospital Leuven, Herestraat 49, B-3000 Leuven, Belgium;

E-mail: steven.joniau@uz.kuleuven.ac.be rates may be due to patient selection, surgeon and hospital volume, and the proportion of nerve-sparing procedures [5, 12-14]. However, non-uniform data-collection, the assessment method, and the definition of potency also influence the reported erectile function outcome [15-17]. A single-item assessment is used in most studies, with potency defined as "having erections firm enough for intercourse." In concordance with the definition of ED introduced by the National Institutes of Health in 1992, ED is therefore the inability to attain and maintain erections firm enough for intercourse [18]. Although this single-item assessment has been used in many recent studies, the IIEF-5 may be a more standardized investigational technique for evaluating ED following RRP. Although it is widely accepted as a valid tool for evaluating $\mathrm{ED}$, the IIEF-5 is used infrequently for the assessment of ED post-RRP [19-21]. We aimed to study the use of the IIEF-5 questionnaire in the evaluation of postoperative ED following nerve-sparing RRP and to compare the results to those obtained using single-item assessment. A questionnaire on the functional outcome of RRP was sent to 272 men who had undergone nerve-sparing RRP, and an extensive chart review was performed.

\section{AIMS}

The aims of this study were to evaluate the use of the IIEF-5 questionnaire for reporting ED following RRP, to 
find possible variations when comparing IIEF-5 to singleitem assessment and to report the functional and oncological results of nerve-sparing RRP at our institution.

\section{PATIENTS AND METHODS}

Two-hundred-and-seventy-two patients underwent open nerve-sparing RRP: $45 \%$ were classified as unilateral- or partial bilateral nerve-sparing (UNS/PBNS) and 55\% as bilateral nerve-sparing (BNS).

\section{Clinical Staging}

Local tumor staging was performed by digital rectal examination, transrectal ultrasound with biopsy, and, in some cases, MRI. Ten at random biopsies were taken from all patients and were scored according to the Gleason scoring system. A bone scan and CT of the pelvis and abdomen were performed to assess bone metastases and lymph node involvement when PSA was $>10 \mathrm{ng} / \mathrm{ml}$, when the clinical stage was T3 or when the Gleason score was $\geq 7$.

\section{Surgical Technique}

Two surgeons (HVP, SJ) performed all procedures. Before performing the radical prostatectomy, all patients underwent a bilateral staging pelvic lymph node dissection without frozen section. The nerve-sparing technique was performed by a modified Walsh tehnique, [3, 22] with avoidance of use of clips and electrocautery near the neurovascular bundle, the accessory pudendal arteries, and the pudendal branch that innervates the extrinsic sphincter of the urethra (which runs dorsal to the sphincter complex).

\section{Pathological Staging}

The RRP specimens, including prostate, seminal vesicles, and bilateral pelvic lymph nodes, were examined microscopically after routine preparation. The prostate was weighed and cut as whole-mount 4-mm sections. All specimens were scored according to the Gleason grading system. Microscopic extension of malignant cells to the inked surface of the resected specimen was interpreted as a positive surgical margin. The pathological stages were recorded as pT2a, pT2b, pT2c, pT3a, pT3b, or pT4 and lymph node status was assigned according to the 2002 TNM classification [23].

\section{Postoperative Care and Follow-Up}

Patients had an indwelling silicone catheter for two weeks. Pelvic floor muscle exercises were started at catheter removal. Patients were evaluated at the outpatient clinic at 6 weeks, 3, 6, and 12 months after surgery, and every 6 months thereafter.

\section{Data Collection}

At a minimum follow-up of 18 months after surgery, a combined questionnaire was mailed to all 272 RRP patients (Appendix). Each patient was asked about pre- and postoperative potency (single-item assessment). Potency was scored as follows: 0: absence of tumescence or presence of erection not rigid enough for penetration (no recovery) or 1: erection that was rigid enough to allow penetration (full recovery). Patients also received an IIEF-5 questionnaire which is an abridged version of the validated International Index of Erectile Function questionnaire. The IIEF-5 consists of four questions derived from the erectile function domain and one question from the intercourse satisfaction domain of the IIEF. A cut-off score of $\geq 22$ (out of 25) points was used as the definition of potency. All patients were also asked about their use of potency-enhancing medication or devices and about their ability to achieve orgasm.

Further, an extensive chart review was performed, and technical aspects of the procedure were noted. These aspects included the surgeon, blood loss, duration, and a score for the technical difficulty of the procedure as determined by the surgeon, ranging from 1 (easy) to 3 (difficult). If nerve preservation was attempted but complicated by bleeding, fibrosis, or other causes, it was noted as partially nerve-sparing on that side. Two categories of nerve-sparing surgery were noted, namely BNS or UNS/PBNS.

\section{Inclusion and Exclusion Criteria}

Patients who received adjuvant therapy and patients who reported an absence of erections rigid enough for intromission (using the single-item assessment) preoperatively were excluded. Using the IIEF-5, nonsexually active patients would be classified as having severe ED, since the score would be 0 for four of the five questions (Appendix). Therefore, for inclusion in the study, patients had to be sexually active.

\section{Statistical Analysis}

We used Cox univariate regression analysis for statistical analysis of the functional outcome predictors. The chi-square test was used for comparison of proportions when comparing outcomes with different definitions of ED. For all evaluations, the level of significance was set at $P=0.05$. For statistical analysis, we used the software MedCalc ${ }^{\circledR}$ (version 8.1.1.0).

\section{RESULTS}

\section{Using the IIEF-5 to Evaluate ED}

A chart review was performed for the 272 patients in the study (Table 1). The mean patient age was $58.2 \pm 6.4$ years (range: 45 to 70 years). Of the 272 patients who underwent RRP, 195 completed and returned the questionnaire; 15 of the 195 patients were excluded because they recieved adjuvant therapy, and 19 of the 195 patients were excluded because preoperatively they had no erections or erections not rigid enough for intromission. Of the remaining 161 patients, 70 were not sexually active when they filled out the questionnaire; thus, only 91 patients were included in the study. Of these 91 patients, $45 \%$ underwent UNS/PBNS; the remaining 55\% had BNS surgery. ED was assessed regardless of whether potency-enhancing devices or medication were used.

We analyzed the influence of the questioning method on reporting of postoperative erectile function in 161 patients, and assessed potency rates in the subgroup of patients that reported being sexually active $(n=91)$. Using single-item assessment to assess whether erections sufficient for intromission were present, the overall full recovery rate was found to be $53.8 \%$. However, of the patients that were sexually 
active, only $25.5 \%$ had an IIEF-5 score of $22-25$ points (i.e. no ED). This difference was statistically significant $(P=$ $0.001)$. This difference in reported results between methods was present in all age groups (Fig. 2) and in the UNS/PBNS as well as the BNS surgery group (Fig. 3). The mean IIEF-5 score in all 91 sexually active patients was 16.27 points (95\% CI: 14.97 to 17.58 ). At the time of the study, $31.2 \%$ of the 91 patients reported use of a PDE-5 inhibitor, $2.5 \%$ used intracavernous injection therapy, and one patient reported using a vacuum tumescence device. Univariate analysis of the predictors for erectile function showed that recovery of

Table 1.

\begin{tabular}{|c|c|c|c|}
\hline \multicolumn{2}{|c|}{ Variable } & $\begin{array}{c}\text { Number } \\
n=272\end{array}$ & $(\%)$ \\
\hline \multicolumn{4}{|l|}{ Patient Characteristics } \\
\hline \multirow[t]{3}{*}{ Age } & $\leq 55$ & 79 & 29,0 \\
\hline & $56-64$ & 123 & 45,2 \\
\hline & $\geq 65$ & 70 & 25,7 \\
\hline \multicolumn{4}{|l|}{ Surgical Characteristics } \\
\hline \multirow[t]{2}{*}{ Procedure } & $\begin{array}{l}\text { bilateral nerve- } \\
\text { sparing }\end{array}$ & 148 & 54,4 \\
\hline & $\begin{array}{l}\text { Unilateral, or bilateral } \\
\text { partial nerve-sparing }\end{array}$ & 124 & 45,6 \\
\hline blood loss & Mean & 684,8 & \\
\hline procedure time & Mean & 90,0 & \\
\hline \multicolumn{4}{|l|}{ Tumor Characteristics } \\
\hline \multirow[t]{4}{*}{ PSA } & $<4 \mathrm{ng} / \mathrm{ml}$ & 31 & 11,7 \\
\hline & $4-10 \mathrm{ng} / \mathrm{ml}$ & 193 & 73,1 \\
\hline & $>10 \mathrm{ng} / \mathrm{ml}$ & 40 & 15,2 \\
\hline & $\begin{array}{l}\text { Mean } \\
\text { Range }\end{array}$ & $\begin{array}{c}7,0 \\
0,50-26,0\end{array}$ & \\
\hline \multirow[t]{3}{*}{ Clinical staging } & $\mathrm{cT} 1 \mathrm{c}$ & 197 & 72,7 \\
\hline & cT2a-c & 68 & 25,1 \\
\hline & сT3a & 6 & 2,2 \\
\hline \multirow[t]{3}{*}{ pathological staging } & HPIN & 3 & 1,1 \\
\hline & pT2 & 239 & 87,9 \\
\hline & pT3 & 30 & 11,0 \\
\hline $\begin{array}{l}\text { Pathological } \\
\text { Gleason score }\end{array}$ & $\begin{array}{l}\text { Median } \\
\text { Mean }\end{array}$ & $\begin{array}{c}7 \\
6.55\end{array}$ & \\
\hline \multirow[t]{6}{*}{ Positive section margins } & Total & 13 & 4,8 \\
\hline & $\mathrm{T} 2 \mathrm{a}$ & 1 & \\
\hline & $\mathrm{T} 2 \mathrm{~b}$ & 2 & \\
\hline & $\mathrm{T} 2 \mathrm{c}$ & 2 & \\
\hline & T3a & 6 & \\
\hline & $\mathrm{T} 3 \mathrm{~b}$ & 2 & \\
\hline
\end{tabular}

potency significantly correlated with perioperative blood loss, age, and prostate volume (Table 2).

Table 2. Correlation of Variables with Erectile Function Outcome (IIEF-5 $\geq 22$ )

\begin{tabular}{|c|c|c|}
\hline Variables & & $\begin{array}{c}\text { IIEF-5 Score } \\
\text { p-Value }\end{array}$ \\
\hline \multirow[t]{5}{*}{ Surgical } & Surgeon & 0,707 \\
\hline & Surgical difficulty score & 0,068 \\
\hline & Blood loss & 0,029 \\
\hline & Duration & 0,472 \\
\hline & Quality of nerve sparing & 0,150 \\
\hline \multirow[t]{2}{*}{ Patient } & Age & 0,013 \\
\hline & Prostate specimen volume & 0,008 \\
\hline \multirow[t]{3}{*}{ Tumor } & Clinical stage & 0,565 \\
\hline & Pathological stage & 0,872 \\
\hline & Gleason score & 0,818 \\
\hline
\end{tabular}

\section{Oncological Outcome}

We used chart review to evaluate the oncological outcomes of all 272 patients who underwent nerve-sparing surgery.

\section{Section Margins}

Of all 272 surgical specimens that were examined 13 $(4.8 \%)$ had microscopic extension of malignant cells to the inked surface. Of those 13 , only 5 had positive section margins on the side were the nerve was spared. Eleven of those 13 patients underwent adjuvant radiation treatment. Two had salvage radiation therapy and hormonal treatment. The other 9 patients received only radiation therapy as adjuvant treatment. Most positive section margins were noted in stage pT3 tumors; $26.7 \%$ of pT3 tumors had positive section margins. In contrast, only $2.1 \%$ of the pT2 tumor specimens had positive section margins.

\section{Biochemical Survival}

When reviewing the charts of the 272 patients, only one patient had a PSA value above $0.2 \mathrm{ng} / \mathrm{ml} 18$ months after surgery, and $4.6 \%$ of patients had detectable PSA.

\section{Adjuvant Therapy}

Postoperatively, radiotherapy was administered to 21 of the 272 patients. Salvage (> 3 months after surgery) radiotherapy was initiated in 10 patients because of rising PSA and adjuvant (started $\leq 3$ months after surgery) radiotherapy was started in 11 patients because of positive section margins. In two patients who received radiotherapy because of positive section margins, hormonal therapy was added because of persisting elevated PSA.

None of the patients died in the first 18 months following surgery. One patient died during further follow-up from a non-cancer related cause. 


\section{DISCUSSION}

The technique for nerve-sparing RRP used at our institution is also referred to as 'anatomical radical prostatectomy' $[3,22]$. This technique reduces blood loss, resulting in better visualization and identification of neurovascular bundles. These bundles arise from the pelvic plexus, and contain noncholinergic non-adrenergic parasympathetic Nitric Oxide Synthase (NOS)-positive nerve fibres and hypogastric nerve fibers. Proximally, these neurovascular bundles lie in close contact with the tip of the seminal vesicles, and extend inferiorly and laterally to the prostate and the urethra to innervate the corpora cavernosa [24]. Even in nerve-sparing surgery, neuropraxia occurs, resulting in degeneration of the nerves and loss of NOS-positive nerve terminals in the corpus cavernosum [25]. This denervation causes neurogenic ED. Secondary to this neurogenic ED, structural changes occur in the corpus cavernosum, including fibrosis, apoptosis, and loss of subtunical smooth muscle mass. These structural changes possibly cause venous leak resulting in venogenic ED [26]. In our series, we found that the reduction in blood loss results in a better functional outcome for the patient. This is likely due to a better preservation of the neurovascular bundles because they are easier to locate, and thus easier to spare, during surgery. Although we strive to avoid the use of hemostatic clips and electrocautery near or on the neurovascular bundles, it is not always possible to avoid this. When blood loss increases, clips may be used to enhance visibility, resulting in damage to the bundles.

Concerning patient selection, we found that age correlated with recovery of erectile function (Fig. 2) as well as with other functional outcome goals (continence and orgasm recovery). Younger patients are expected to have less vascular pathology and other comorbidities and have greater erectile capacity and neural regenerative ability than did older patients; this illustrates why patient selection can have a significant impact on the functional outcome of nerve-sparing radical prostatectomy. We found that approximately onethird of patients used medical aids to achieve and maintain erections, mostly PDE-5 inhibitors. Patients did not follow a standardized penile rehabilitation program. Single-item assessment showed higher erectile function recovery rates in sexually active patients $(36.1 \%$ recovery for all 161 patients that returned the questionnaire, and $53.8 \%$ in sexually active patients), as was previously published by Geary et al. [27]. Recovery of erections sufficient for intromission in $53.8 \%$ of sexually active patients is similar to outcomes reported by others, taking into account that $45 \%$ of the patients in this group did not have BNS surgery.

Nerve-sparing surgery achieved satisfactory oncological results, with only $7.7 \%$ of all patients requiring adjuvant or salvage therapy. Of $13(4.8 \%)$ patients with positive section margins, 8 were stage pT3 tumors; only 5 patients had positive margins at the nerve-sparing side.

\section{The Use of the IIEF-5 Questionnaire to Evaluate Post- RRP ED}

In 1999 , the IIEF-5 was developed by Rosen et al. to assess the presence and severity of ED, and was stated to possess favorable properties for the detection and classification of ED. In that report, an IIEF-5 score of 21 was found to discriminate between ED versus no ED in the 1152 men that were studied [19]. In 2005, Karakiewicz et al. studied the reliability of remembered IIEF domain scores pre-RRP, and 6 and 12 months post-RRP, in 39 men with localized prostate cancer; they concluded that the remembered IIEF erectile function domain score (IIEF-EF) demonstrated high reliability with prospectively collected data [21]. The IIEF-5, which largely overlaps the IIEF-EF, thus seems a reliable instrument to use retrospectively for the analysis of ED in men who undergo nerve-sparing RRP. However, when reviewing studies performed since 1999 on post-RRP ED, we found that the IIEF-5 was used in only a minority of the (pro- and retrospective) studies. In most reports, the definition used for potency was: "having erections firm enough for intercourse", a definition that provides a 'black and white' measure of erectile function (single-item assessment). In contrast, the IIEF-5 score reflects not only penile function per se, but also measures patient satisfaction and confidence [19]. Furthermore, by evaluating erection maintenance frequency and maintenance ability after intromission, the IIEF5 assesses penile function more thoroughly than does singleitem assessment. In 2000, Cappelleri et al. found a moderateto-high correlation between the IIEF erectile function domain score and patients' self-assessment of ED by singleitem assessment, which we were able to reproduce in our series for the IIEF-5 (Fig. 1) [20]. Cappelleri et al. stated that although a single-item assessment is likely to have a higher response rate, the IIEF erectile function domain score is expected to have a higher level of validity, accuracy, and reliability, and is a more stable measurement than the singleitem self-assessment. In the current study, the difference in potency rate between age groups was more pronounced when using the IIEF-5 score than when using single-item assessment (Fig. 2). However, because of the relatively small study population, we were not able to confirm this statistically. Concerning the difference in potency rates in the $\mathrm{UNS} / \mathrm{PBNS}$ vs. the BNS group, we found the relative difference between the two groups to be $16 \%$ using the single-item assessment and $126 \%$ using the IIEF-5 (Fig. 3). This fact seems to indicate a higher level of accuracy as was suggested by Cappelleri et al. [20].

We aimed to study the functional outcome of nervesparing RRP using the IIEF-5 as an instrument for evaluation compared to single-item assessment. In the group of 91 sexually active men at a minimum of 18 months postoperatively, we found that only $25.5 \%$ had no ED (i.e. an IIEF-5 score of 22-25). In the UNS/PBNS group, $15 \%$ had no ED vs. $34 \%$ in the BNS group. This illustrates an important discordance in reporting on erectile function outcome of nervesparing RRP when using different definitions for ED in the same patient population. This finding was also previously described by Krupski et al. [15]. In agreement with Walsh, we think that using such a scoring system confers minimal benefit to the patient; however, the introduction of the IIEF or IIEF-5 as a standard evaluation method for functional RRP outcome is likely to allow comparison of various series, and comparison of the outcomes of non-nerve-sparing, UNS, and BNS surgery $[15,28]$. This discordance may be the main reason why IIEF-5 is not used frequently in studies of postRRP ED. We assume that the differences in the percentages of reported ED are based on the fact that the IIEF-5 evaluates other parameters in addition to intromission. Noldus et al. found that in the group of patients that reported erections 


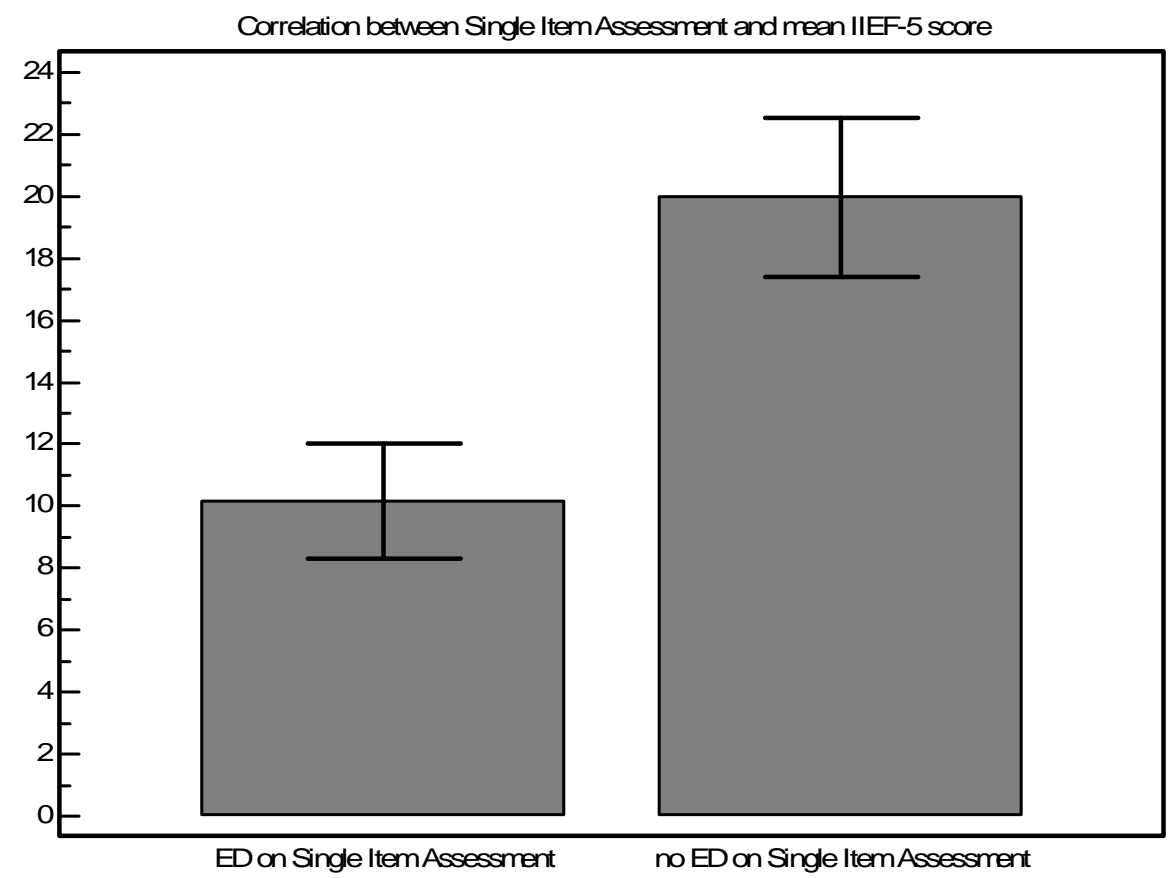

Fig. (1). There is a significant correlation between IEFF-5 and single-item assessment outcome scores. Note that the mean IIEF-5 score in the group with no ED on single-item assessment is only 20.44, indicating mild ED according to the scoring convention of Rosen $e t$ al.

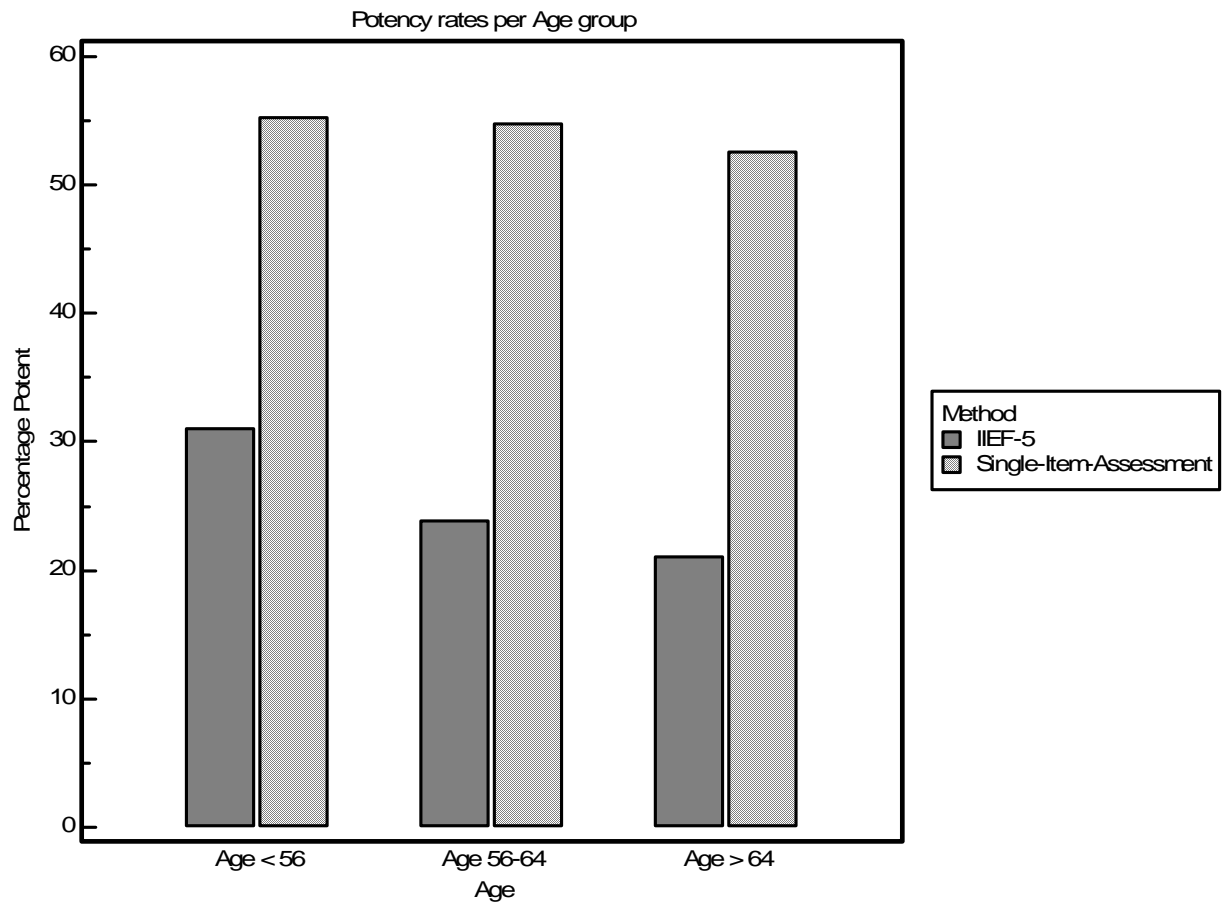

Fig. (2). There is a correlation between potency and age, and different definitions for potency result in different potency rates. The decline of potency rates in older age groups is more pronounced using the IIEF-5 definition versus the single-item assessment definition. This difference did not attain statistically significance because of the relatively small study population $(\mathrm{n}=91)$.

rigid enough to be satisfactory for sexual intercourse using a single-item assessment, the average IIEF-5 score was 19.9, which indicates mild ED [8]. The lower average score using the IIEF-5 illustrates that the use of the IIEF-5 produces less optimistic results compared to the single-item assessment score. This is consistent with our findings: We found an average IIEF-5 score of 20.4 (mild ED) in the group that reported having erections sufficient for intromission on the single-item assessment score.
One major disadvantage of the IEFF-5 is that it can only be used to evaluate patients who are sexually active, since nonsexually active patients will be categorized as having severe ED, which is not always true. Patients who are temporarily nonsexually active can thus be classified as having severe ED while in fact they are perfectly capable of attaining and maintaining an erection sufficient for intromission. This is a concern when evaluating patients preoperatively, when they have only recently been diagnosed with cancer; 


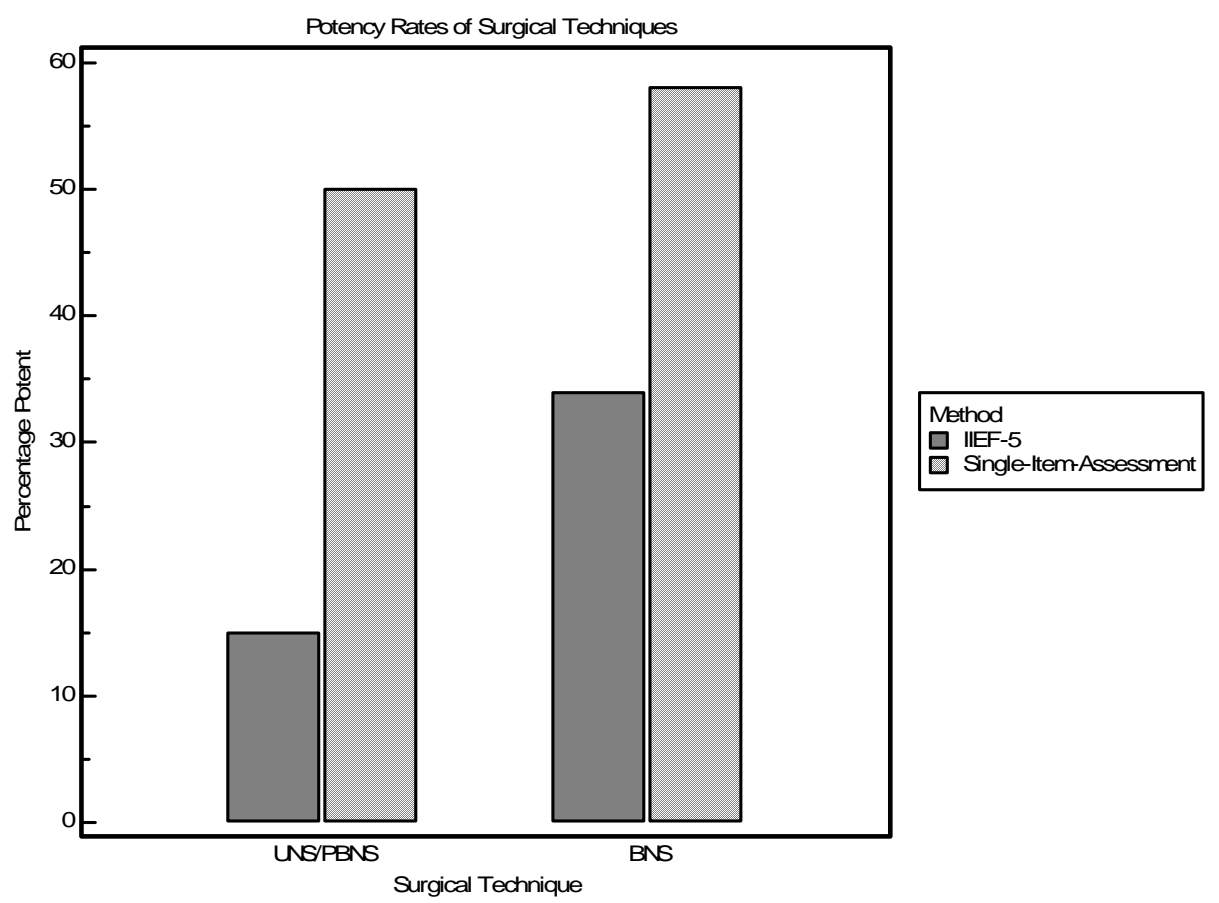

Fig. (3). Potency according to surgical technique (UNS/PBNS: unilateral- or partial nerve-sparing; BNS: bilateral nerve-sparing). There was a significant difference between the potency rates depending on the definition of potency $(P=0.001)$. There was a relative difference between the two groups of $16 \%$ using single-item assessment versus $126 \%$ using the IIEF-5 definition.

the diagnosis itself can result in loss of sexual interest and activity [29-33]. The present study has some limitations. Firstly, a retrospective study may not be optimal to address this topic. However, it is a good instrument to get an impression of the discordance between single-item assessment and IIEF-5 score. Secondly, the fact that pre-operative potency was evaluated by a remembered single-item assessment is also a major drawback. This could create considerable recall bias. To our knowledge, no data are currently available on remembered single-item assessment scores, however recent data indicates that remembered IIEF should not be used to assess SF in a real-life clinical setting in candidates for radical prostatectomy [33]. We assume this finding also could be true for the IIEF-5 score.

\section{CONCLUSIONS}

Increased detection of organ-confined prostate cancer has increased the demand for nerve-sparing surgery. In our insti- tution, we found that nerve-sparing RRP resulted in satisfactory oncological and functional outcomes. We studied the use of the validated IIEF-5 questionnaire for reporting ED following nerve-sparing surgery, and found that a significantly lower percentage of men were classified as having no ED compared to single-item assessment. This may explain why the IIEF-5 is not used more frequently in studies of ED post-RRP. However, the IIEF-5 has a higher level of validity, accuracy, and reliability, and is more stable than the single-item assessment. We therefore think it is an excellent instrument for reporting on erectile function following radical prostatectomy. A prospective comparison between IIEF5 and single-item assessment is needed to confirm this finding. It should be kept in mind that in comparing different studies, comparisons of patient selection, hospital and surgeon volume, and the overall proportion of nerve-sparing surgeries are as important as the questionnaire and definition of potency that are used.

\section{APPENDIX: QUESTIONNAIRE}

\section{Sexual Function (Single-Item Assessment and Orgasm)}

\begin{tabular}{|l|l|}
\hline 1a. Which of these statements fits best with your status before your prostate was excised? & Score \\
\hline \hline - I was not able to get an erection & 0 \\
\hline - I was able to get an erection, but it was not rigid enough for penetration & 0 \\
\hline - I was able to get an erection which was rigid enough for penetration & 1 \\
\hline 1b. Which of these statements fits best with your current status? & 0 \\
\hline - I am not able to get an erection & 0 \\
\hline - I am able to get an erection, but it is not rigid enough for penetration & 1 \\
\hline - I am able to get an erection which is rigid enough for penetration & 0 \\
\hline
\end{tabular}




\begin{tabular}{|l|l|}
\hline 2a. Were you able to have the sensation of orgasm before your prostate was excised? & \\
\hline \hline - No & 0 \\
\hline - Yes & 1 \\
\hline 2b. Are you currently able to have the sensation of orgasm? & \\
\hline \hline - No & 0 \\
\hline - Yes & 1 \\
\hline
\end{tabular}

\section{Use of Potency-Enhancing Medication or Devices}

1. Do you use aids to improve your potency?

- Yes, Viagra ${ }^{\circledR}$ (Sildenafil)

- Yes, Levitra ${ }^{\circledR}$ (Vardenafil)

- Yes, Cialis ${ }^{\circledR}$ (Tadalafil)

- Yes, injections in the base of the penis

- Yes, a vacuum-device

- No

2. If you use oral medication to improve your potency, what is the dose you use?

\begin{tabular}{|c|c|}
\hline - Viagra ${ }^{\circledR}$ (Sildenafil) & $\begin{array}{l}25 \mathrm{mg} . \\
50 \mathrm{mg} . \\
100 \mathrm{mg} .\end{array}$ \\
\hline - Levitra ${ }^{\circledast}$ (Vardenafil) & $\begin{array}{l}5 \mathrm{mg} . \\
10 \mathrm{mg} . \\
20 \mathrm{mg} .\end{array}$ \\
\hline - Cialis ${ }^{\circledast}$ (Tadalafil) & $\begin{array}{l}10 \mathrm{mg} . \\
20 \mathrm{mg}\end{array}$ \\
\hline
\end{tabular}

\section{IIEF-5}

1. How do you rate your confidence that you could get and keep an erection?

\begin{tabular}{|l|c|}
\hline \hline - Very low & 1 \\
\hline - Low & 2 \\
\hline - Moderate & 3 \\
\hline - High & 4 \\
\hline- Very High & 5 \\
\hline
\end{tabular}

\section{When you had erections with sexual stimulation, how often were your erections hard enough for penetration?}

- I am currently not sexually active

- Never or almost never

- A few times (less than half of the attempts)

- Sometimes (approximately half of the attempts)

- Most times (more than half of the attempts) 
(APPENDIX) contd....

\begin{tabular}{|l|c|}
\hline 3. During sexual intercourse, how often were you able to maintain your erection after you had penetrated (entered) your partner? & 0 \\
\hline \hline - I am currently not sexually active & 1 \\
\hline - Never or almost never & 2 \\
\hline - A few times (less than half of the attempts) & 3 \\
\hline - Sometimes (approximately half of the attempts) & 4 \\
\hline - Most times (more than half of the attempts) & 5 \\
\hline - Always or almost always & 5 \\
\hline
\end{tabular}

4. During sexual intercourse, how difficult was it to maintain your erection to completion of intercourse?

- I am currently not sexually active

- Extremely difficult

- Very difficult

- Difficult

- Slightly difficult

- Not difficult

\section{When you attempted sexual intercourse, how often was it satisfactory for you?}

\begin{tabular}{|l|l|}
\hline \hline - I am currently not sexually active & 0 \\
\hline - Never or almost never & 1 \\
\hline - A few times (less than half of the attempts) & 2 \\
\hline - Sometimes (approximately half of the attempts) & 3 \\
\hline - Most times (more than half of the attempts) & 4 \\
\hline - Always or almost always & 5 \\
\hline
\end{tabular}

\section{Adjuvant Treatment}

1 After your surgical treatment, did you receive any other form of treatment for prostate cancer?

\begin{tabular}{|l|l|}
\hline \hline - No & \\
\hline - Yes, radiation therapy & \\
\hline - Yes, hormonal treatment & \\
\hline - Yes, both I received both radiation therapy as hormonal treatment & \\
\hline
\end{tabular}

\section{REFERENCES}

[1] Ferlay J, Autier P, Boniol M, Heanue M, Colombet M, Boyle P. Estimates of the cancer incidence and mortality in Europe in 2006. Ann Oncol 2007; 18(3): 581-92.

[2] Walsh PC, Donker PJ. Impotence following radical prostatectomy: insight into etiology and prevention. J Urol 1982; 128(3): 492-7.

[3] Walsh PC. Anatomic radical retropubic prostatectomy. In: Walsh PC, Retik AB, Stamey TA, et al. Eds. Campbell's Textbook of Urology. $7^{\text {th }}$ ed. WB Saunders, Philadelphia 1997; pp. 2565-88.

[4] Van der AF, Joniau S, De Ridder D, Van Poppel H. Potency after unilateral nerve sparing surgery: a report on functional and on- cological results of unilateral nerve sparing surgery. Prostate Cancer Prostatic Dis 2003; 6(1): 61-5.

[5] Kundu SD, Roehl KA, Eggener SE, Antenor JA, Han M, Catalona WJ. Potency, continence and complications in 3,477 consecutive radical retropubic prostatectomies. J Urol 2004; $172(6$ Pt 1): 2227 31.

[6] Saranchuk JW, Kattan MW, Elkin E, Touijer AK, Scardino PT, Eastham JA. Achieving optimal outcomes after radical prostatectomy. J Clin Oncol 2005; 23(18): 4146-51.

[7] Stanford JL, Feng Z, Hamilton AS, et al. Urinary and sexual function after radical prostatectomy for clinically localized prostate cancer: the prostate cancer outcomes study. JAMA 2000; 283(3): 354-60. 
[8] Noldus J, Michl U, Graefen M, Haese A, Hammerer P, Huland H. Patient-reported sexual function after nerve-sparing radical retropubic prostatectomy. Eur Urol 2002; 42(2): 118-24.

[9] Graefen M, Walz J, Huland H. Open retropubic nerve-sparing radical prostatectomy. Eur Urol 2006; 49(1): 38-48.

[10] Deliveliotis C, Delis A, Papatsoris A, Antoniou N, Varkarakis IM. Local steroid application during nerve-sparing radical retropubic prostatectomy. BJU Int 2005; 96(4): 533-5.

[11] Walsh PC, Marschke P, Ricker D, Burnett AL. Patient-reported urinary continence and sexual function after anatomic radical prostatectomy. Urology 2000; 55(1): 58-61.

[12] Van Poppel H, Boulanger SF, Joniau S. Quality assurance issues in radical prostatectomy. Eur J Surg Oncol 2005; 31(6): 650-5.

[13] Zippe C, Nandipati K, Agarwal A, Raina R. Sexual dysfunction after pelvic surgery. Int J Impot Res 2006; 18(1): 1-18.

[14] Begg CB, Riedel ER, Bach PB, et al. Variations in morbidity after radical prostatectomy. N Engl J Med 2002; 346(15): 1138-44.

[15] Krupski TL, Saigal CS, Litwin MS. Variation in continence and potency by definition. J Urol 2003; 170(4 Pt 1): 1291-4.

[16] Talcott JA, Rieker P, Propert KJ, et al. Patient-reported impotence and incontinence after nerve-sparing radical prostatectomy. J Natl Cancer Inst 1997; 89(15): 1117-23.

[17] Briganti A, Salonia A, Gallina A, et al. Potency after radical prostatectomy: from new techniques to better results. EAU-EBU Update Ser 2006; 4(1): 33-45.

[18] NIH Consensus Conference. Impotence. NIH Consensus Development Panel on Impotence. JAMA 1993; 270(1): 83-90.

[19] Rosen RC, Cappelleri JC, Smith MD, Lipsky J, Pena BM. Development and evaluation of an abridged, 5 -item version of the International Index of Erectile Function (IIEF-5) as a diagnostic tool for erectile dysfunction. Int J Impot Res 1999; 11(6): 319-26.

[20] Cappelleri JC, Siegel RL, Osterloh IH, et al. Relationship between patient self-assessment of erectile function and the erectile function domain of the International Index of Erectile Function. Urology 2000; 56: 477-81.

[21] Karakiewicz P, Shariat SF, Naderi A, et al. Reliability of remembered international index of erectile function domain scores in men with localized prostate cancer. Urology 2005; 65: 131-5.
[22] Hsu CY, Joniau S, Van Poppel H. Radical prostatectomy for locally advanced prostate cancer: technical aspects of radical prostatectomy. EAU Update Ser 2005; 3: 90-7.

[23] Sobin LH, Wittekind C. TNM classification of prostate cancer. $6^{\text {th }}$ ed. New York, Wiley Liss 2002; pp. 184-7.

[24] Yucel S, Erdogru T, Baykara M. Recent neuroanatomical studies on the neurovascular bundle of the prostate and cavernosal nerves: clinical reflections on radical prostatectomy. Asian J Androl 2005; 7(4): 339-49.

[25] Carrier S, Zvara P, Nunes L, Kour NW, Rehman J, Lue TF. Regeneration of nitric oxide synthase-containing nerves after cavernous nerve neurotomy in the rat. J Urol 1995; 153(5): 1722-7.

[26] Albersen M, Joniau S, Claes H, Van Poppel H. Preclinical evidence for the benefits of penile rehabilitation therapy following nervesparing radical prostatectomy. Adv Urol 2008; 594868.

[27] Geary ES, Dendinger TE, Freiha FS, Stamey TA. Nerve sparing radical prostatectomy: a different view. J Urol 1995; 154(1): 145-9.

[28] Walsh PC. Re: variation in continence and potency by definition. J Urol 2004; 171(4): 1635.

[29] Edwards B, Clarke V. The psychological impact of a cancer diagnosis on families the influence of family functioning and patients' illness characteristics on depression and anxiety. Psychooncology 2004; 13: 562-76.

[30] Briganti A, Gallina A, Salonia A, et al. Reliability of classification of erectile function domain of the international index of erectile function in patients affected by localized prostate cancer who are candidates for radical prostatectomy. Urology 2005; 66(5): 1140-1.

[31] Salonia A, Zanni G, Gallina A, et al. Baseline potency in candidates for bilateral nerve-sparing radical retropubic prostatectomy. Eur Urol 2006; 50(2): 360-5.

[32] Papadoukakis S, Kusche D, Stolzenburg JU, Truss MC. Reconsidering the use of the international index of erectile function questionnaire in evaluating the preoperative erectile function status of patients undergoing radical prostatectomy. BJU Int 2007; 100(2): 368-70.

[33] Salonia A, Gallina A, Briganti A, et al. Remembered international index of erectile function domain scores are not accurate in assessing preoperative potency in candidates for bilateral nerve-sparing radical retropubic prostatectomy. J Sex Med 2008; 5(3): 677-83.

(C) Albersen et al.; Licensee Bentham Open.

This is an open access article licensed under the terms of the Creative Commons Attribution Non-Commercial License (http://creativecommons.org/licenses/ by-nc/3.0/) which permits unrestricted, non-commercial use, distribution and reproduction in any medium, provided the work is properly cited. 